Published in final edited form as:

J Am Chem Soc. 2018 December 19; 140(50): 17349-17355. doi:10.1021/jacs.8b09677.

\title{
Nickel-Catalyzed Reductive [2+2] Cycloaddition of Alkynes
}

\author{
Santiago Cañellas ${ }^{\dagger, \S}$, John Montgomery\#, and Miquel À. Pericàs ${ }^{\dagger, \ddagger},{ }^{*}$ \\ †Institute of Chemical Research of Catalonia (ICIQ), The Barcelona Institute of Science and \\ Technology, Avda. Països Catalans 16, E-43007, Tarragona, Spain \\ ‡Departament de Química Inorgànica i Orgànica, Universitat de Barcelona, 08028, Barcelona, \\ Spain \\ §Universitat Rovira i Virgili, Departament de Química Analítica i Química Orgànica, Marcel.lí \\ Domingo, 1, 43007 Tarragona, Spain \\ \#Department of Chemistry, University of Michigan, 930 North University Avenue, Ann Arbor, MI \\ 48019-1055, United States
}

\begin{abstract}
The nickel-catalyzed synthesis of tetrasubstituted cyclobutenes from alkynes is reported. This transformation is uniquely promoted by the use of a primary aminophosphine, an unusual ligand in nickel catalysis. Mechanistic insights for this new transformation are provided, and post-reaction modifications of the cyclobutene products to stereodefined cyclic and acyclic compounds are reported, including the synthesis of epi-truxillic acid.
\end{abstract}

\section{Graphical Abstract}
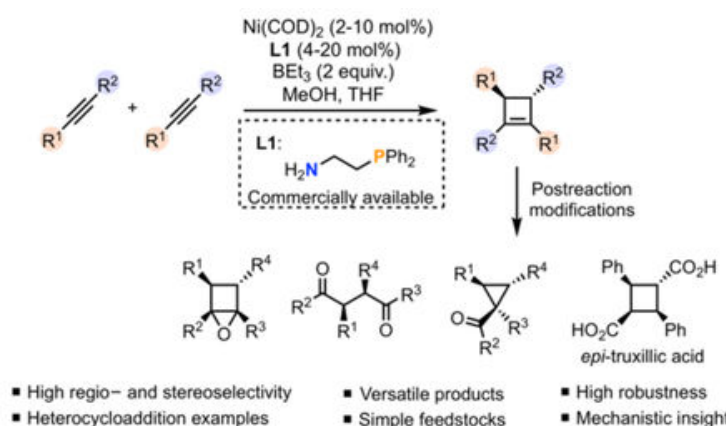

*Corresponding Author: To whom correspondence should be addressed: mapericas@iciq.es.

The Supporting Information is available free of charge on the ACS

Publications website.

Experimental procedures and spectral data (PDF)

Crystallographic data for $\mathbf{4 a}$ (CIF)

Crystallographic data for $\mathbf{4 b}(\mathrm{CIF})$

Crystallographic data for $\mathbf{1 0}(\mathrm{CIF})$

Notes

The authors declare no competing financial interest. 
Since the pioneering work by Reppe and Wilke on the cyclotetramerization of acetylene and ensuing ligand-influenced outcomes in catalytic cycloadditions, ${ }^{1}$ nickel catalysis has contributed to the development of many $\mathrm{C}-\mathrm{C}$ and $\mathrm{C}-$ heteroatom bond-forming processes. ${ }^{2}$ Building on these early studies, nickel-catalyzed methods have led to many advances in cycloadditions, allowing the assembly of various ring sizes from simple $\pi$-components depending on the ligand system and precursors employed. ${ }^{2 \mathrm{a}, 2 \mathrm{~d}}$ While the assembly of sixand eight-membered rings have been well developed, accessing cyclobutane and cyclobutene products is more limited and typically requires conjugated and activated substrates such as allenes, 1,3-enynes, or strained rings such as norbornene derivatives. The assembly of cyclobutanes and cyclobutenes by the catalytic cycloaddition of simple, non-conjugated $\pi$ components has thus proven elusive by using existing methods.

Cyclobutenes in particular are highly versatile synthetic intermediates because of their ring strain and high reactivity. ${ }^{3}$ In addition, they are also found in many bioactive metabolites, natural products, drugs, and organic dyes. ${ }^{4}$ In recent years, much progress has been made in strategies for the direct formation of the cyclobutene skeleton. Most commonly, the catalytic synthesis of cyclobutenes involves the use of an alkene-alkyne [2+2]-cycloaddition reaction typically involving conjugated and activated substrates (Figure 1a). Using this approach, many useful methodologies have been reported using transition metal ${ }^{5-6}$ and Lewis acid ${ }^{7}$ catalysis. An alternate approach involves the reductive cyclodimerization of two alkynes. This latter approach has been developed using a zirconium-mediated pyridine-directed strategy (Figure 1b), ${ }^{8}$ but variations of this process that involve sub-stoichiometric catalyst loadings or simple alkynes that lack directing groups have not been previously described. Despite the advances realized, the development of an intermolecular catalytic route with two different alkyne coupling partners is currently not available. We recognized that such a process would provide new opportunities for rapidly building up useful synthetic intermediates from simple starting materials.

In the course of exploring new types of catalytic additions to alkynes, we unexpectedly found that the reductive dimerization of alkynes to produce cyclobutenes is the major pathway when primary aminophosphine ligands are employed. (Figure 1c). Primary $\beta$ aminophosphines have rarely been used as ligands in catalysis, ${ }^{9}$ and are not typically employed in ligand screens of nickel-catalyzed processes. The reactivity is notable given that many nickel-catalyzed reductive transformations have been described with alkynes, whereas the alkyne reductive cyclodimerization has not previously been described. Other cycloadditions and reductive couplings involving nickel catalysis typically involve monodentate phosphines or NHC ligands, ${ }^{2 \mathrm{~d}}$ suggesting that the unique behavior of primary aminophosphines will serve as an important counterpart to these well-studied catalytic systems. Given the novelty and potential utility of the reductive cyclodimerization of alkynes in the assembly of stereo- and regiochemically-defined cyclobutenes, as well as the lack of information about the unique reactivity of nickel complexes of primary aminophosphines, we report here the development, scope, and mechanistic insights of this newly discovered process.

We began our investigations by studying the reaction of 1a in a High Throughput Experimentation (HTE) platform with $\mathrm{Ni}(\mathrm{COD})_{2}$. We screened a wide variety of ligands 
(L1-L23) such as aminophosphines, phosphoramidites, phosphines, amines, heterocyclic amines, NHCs and diols (Table 1, entries 4-5), several Brønsted acids such as methanol, isopropanol and benzoic acid (Table 1, entries 4, 11-12), and reducing agents such as triethylborane and dimethylphenylsilane (Table 1, entries 4 and 14). ${ }^{10}$ Interestingly, we only found significant amounts ( $>10 \%$ yield) of the desired cyclobutene 2a with a combination of the primary aminophosphine ligand $\mathbf{L} \mathbf{1}$, methanol or isopropanol, and triethylborane. Notably, traces of product were found with a binary ligand system consisting of a primary amine $\left(\mathrm{BuNH}_{2}\right)$ and a tertiary phosphine $\left(\mathrm{PPh}_{3}\right)$, thus reinforcing the need for a tethered aminophosphine backbone. No significant amount of cyclobutene product was observed when using $\mathrm{NiCl}_{2}$ reduced in situ by $\mathrm{Mn}$ or $\mathrm{Zn}$ (Table 1, entry 15) or the corresponding control experiments (Table 1, entries 2-3).

Several ligands of this class (L1, L24-L28) were screened on a preparative scale (Table 1, entries 6-11), after which $\mathbf{L} 1$ was revealed as the ligand of choice. After further optimization of reaction conditions, ${ }^{10}$ the head-to-tail trans-cyclobutene $\mathbf{2 a}$ was obtained in $73 \%$ isolated yield. Excellent regio- and stereoselectivities were observed, and all reagents and catalysts are commercially available, thus making the procedure simple and selective for the desired cyclobutenes.

We then turned our attention to the generality of this transformation. First, a robustness screen was performed, showing a high functional group tolerance. ${ }^{11}$ Then, a series of examples of nickel-catalyzed reductive [2+2] cycloadditions of alkynes to produce transcyclobutenes were illustrated under optimized conditions (Scheme 1). The reaction was efficient with alkynes bearing alkyl groups with different chain lengths (2a-d). Electronic properties of the alkyne were evaluated by introducing electron-withdrawing and electrondonating groups on the aryl moiety. Although electron rich alkynes (2f and $\mathbf{2 h}$ ) underwent coupling faster than electron-poor ones ( $\mathbf{2 g})$, the desired cyclobutene was successfully obtained in all cases. The reaction was effective in the presence of unprotected polar

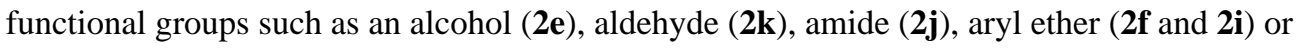
amine (2h). Alkynes bearing heterocyclic moieties such as 2-pyridyl (2l-m), 2-pyrimidinyl (2n) and 2-thiazolyl (2o) also gave rise to the desired cyclobutenes. TMS-alkynes showed a silyl group migration on the cyclobutene products $(\mathbf{2} \mathbf{p}$ and $\mathbf{2 q}) \cdot{ }^{12}$ Surprisingly, aldehyde/ alkyne reductive coupling ${ }^{13}$ or demethoxylation ${ }^{14}$ pathways were not observed. The scalability of this protocol was tested through synthesis of the cyclobutene $2 \mathbf{e}$ on a 2-gram scale. In this case, the catalyst loading was successfully lowered to $2 \mathrm{~mol} \%$ and the desired cyclobutene was obtained in $62 \%$ isolated yield.

The suppression of alkyne homocoupling presents a clear challenge in the development of synthetically desirable reductive heterocouplings of two different alkynes. ${ }^{16}$ In order to explore the feasibility of this approach, alkynes of different electronic and steric properties were examined to achieve the desired cross-reductive [2+2] alkyne cycloaddition. First, we attempted the reaction using two electronically opposed alkynes, $\mathbf{1 g}$ and $\mathbf{1 f}$. To our delight, the corresponding heterocoupling product $2 \mathbf{r}$ was obtained in $62 \%$ yield, accompanied by minor amounts of the homocoupling products (7\% of $\mathbf{2 g}$ and $21 \%$ of $\mathbf{2 f}$ ). Nonetheless, the two regioisomers arising from the position of the double bond in the cyclobutene ring were formed in 1:1 ratio. Then, we subjected the steroid phenyl-17a-ethynylestradiol $1 \mathrm{~s}$ to the 
reductive [2+2] cycloaddition reaction with 1a. Due to the bulkiness of the steroid, it was unreactive towards the reductive homo-cyclodimerization. This allowed us to perform the heterocoupling in a very clean manner by slowly adding the alkyne 1a via syringe pump. The corresponding hetero-coupling product $2 \mathrm{~s}$ was obtained in 59\% yield (10:1 d.r.), with $40 \%$ of the starting material $1 \mathbf{s}$ being recovered. Furthermore, diphenylacetylene 3a gave rise to the cis,cis-diene 4a in good yield (Scheme 2a). ${ }^{17 a}$ We also attempted the cyclization of diynes to form bicyclic cyclobutenes (Scheme $2 b$ ). In both cases, the dienes $\mathbf{4 b}$ and $\mathbf{4 c}$ were obtained as the major products in good yields. ${ }^{18}$ The isomer obtained in products $\mathbf{4 a - c}$ suggests the formation of the trans-cyclobutene followed by a thermal conrotatory electrocyclic ring-opening step. ${ }^{17}$

The potential synthetic utility of this protocol was then demonstrated through the diversification of the cyclobutene products (Scheme 3). First, ozonolysis of cyclobutene 2a afforded the stereodefined acyclic 1,4-diketone $\mathbf{5}$ as a single isomer. ${ }^{19}$ On the other hand, epoxidation of 2a gave rise to the cyclobutane epoxide $\mathbf{6}$ in good yield and 4:1 $\mathrm{dr}^{20}$ This product was then subjected to acidic conditions to perform a ring-contraction, thus affording the cyclopropyl ketone 7 in good yield and excellent diastereomeric ratio. ${ }^{21}$ Finally, we targeted the synthesis of epi-truxillic acid, a naturally occurring cyclobutanedicarboxylic acid with interesting biological properties. ${ }^{22,23}$ To our delight, the hydrogenation of cyclobutene $2 \mathbf{e}$ to cyclo-butane $\mathbf{8}$ took place with exquisite diastereoselectivity, with $\mathbf{8}$ being isolated as a single isomer in good yield. ${ }^{24}$ Finally, Jones oxidation afforded the corresponding epi-truxillic acid $\mathbf{9}$ in quantitative yield. ${ }^{25,26}$

A number of experiments were conducted to shed light on the mechanistic features of this reductive cyclodimerization process. Deuterium-labelling studies displayed 90-92\% deuterium incorporation using $\mathrm{CD}_{3} \mathrm{OD}$ and $\mathrm{CH}_{3} \mathrm{OD}$ in a regio- and stereoselective manner. On the other hand, no deuterium incorporation was observed using $\mathrm{CD}_{3} \mathrm{OH}$ (Scheme $4 \mathrm{a}$ ). With these results in hand, we performed the kinetic analysis of two parallel reactions run using $\mathrm{CD}_{3} \mathrm{OD}$ and $\mathrm{CH}_{3} \mathrm{OH}$ respectively. A primary kinetic isotope effect (KIE) of 3.0 was observed, indicating that a proton transfer is involved in the rate-determining step. ${ }^{27}$ Motivated by the different reaction rate of electron-poor and electron-rich alkynes, we studied linear free-energy relationships to unveil potential cationic or anionic intermediates. The reactions using substrates $\mathbf{1 a}, \mathbf{1 f}, \mathbf{1 g}$ and $\mathbf{1 h}$ were monitored by ${ }^{1} \mathrm{H}$-NMR to determine the corresponding kinetic behaviors (Scheme 4b). The observed Hammett plots, characterized by $\rho<0$, suggest that a positive charge accumulates in the rate-determining step. $^{28}$

With this mechanistic information in hand, a plausible catalytic cycle is proposed for this reaction (Scheme 5). After rapid ligand exchange with $\mathbf{L 1}$ (I) and coordination of two alkynes to the nickel center (II) ${ }^{29} \mathrm{Ni}(0)$ may undergo an oxidative cyclization to form the first $\mathrm{C}-\mathrm{C}$ bond, generating the nickelacycle (III). ${ }^{1,2 \mathrm{a}, 30}$ Then, the methanol-triethylborane adduct could protonate ${ }^{31}$ the $\pi$-system generating a stabilized cationic nickel carbene IV. ${ }^{32,33}$ Next, a 1,2-alkyl migration would generate the 4-membered ring and the second $\mathrm{C}-\mathrm{C}$ bond (V) ${ }^{12,34}$ Finally, an ethyl transfer to nickel (VI), $\beta$-hydride elimination ${ }^{35}(\mathbf{V I I})$ and reductive elimination ${ }^{36}$ gives rise to the desired cyclobutene, regenerating the nickel( $(0)$ catalyst. In situ HRMS (ESI+) analysis of the reaction mixture using alkyne 1e revealed a 
very intense $\mathrm{m} / \mathrm{z}$ signal at 552.1609 with the characteristic isotopic distribution of a nickel species. This data suggests the presence of a nickel species that incorporates the aminophosphine and the two units of the corresponding alkyne (i.e. structures II-V). In combination with the Hammett studies and KIE experiments, the data overall is consistent with III being the catalyst resting state.

This overall mechanism bears analogy to [3+2] reductive cycloadditions of enals and alkynes that proceed through the protonation of enolate motifs embedded with a nickel metallacycle. ${ }^{37-38}$ However, the only previous examples where metallacyclopentadienes are converted to cyclobutenes are the stoichio-metric zirconium-mediated processes described above. ${ }^{8}$ Notably, protonation of a $\mathrm{Ni}(\mathrm{II})$ metallacyclopentene species by a water/borate adduct $^{31 \mathrm{a}}$ and the protonation of $\mathrm{Ni}(0)$ species by a similar methanol/borane mixture ${ }^{31 \mathrm{~b}-\mathrm{c}}$ have recently been proposed in the hydroalkylation and hydroarylation of allenes, styrenes and dienes under similar conditions to our study. ${ }^{31}$ Although $\mathrm{Ni}(0)$ protonation would be expected to be faster than protonation of III, products resulting from hydroalkylation or reduction of the alkyne are only observed as minor by-products. Furthermore, exogeneous alkenes such as styrene and $E / Z$ - $\beta$-methylstyrene are not incorporated in the cyclobutene products, ${ }^{39}$ suggesting that nickel hydride mediated reduction of the alkyne and subsequent alkene-alkyne [2+2] cycloaddition reaction is unlikely for the production of cyclobutene products. The basis for the unique promotion exhibited by the aminophosphine $\mathbf{L 1}$ is currently unclear. The role of this ligand architecture may involve features other than simple bidentate coordination, such as proton shuttling or generation of a Lewis adduct with the borane component, and further studies to understand the unique behavior of this ligand class are in progress.

In summary, a nickel-catalyzed reductive [2+2] cycloaddition reaction of alkynes towards the synthesis of trans-cyclobutenes has been developed. The use of an unusual primary aminophosphine ligand was key to the discovery of this new reaction. Post-reaction modifications highlighted the synthetic versatility of these products, including the synthesis of the natural product epi-truxillic acid.

\section{Supplementary Material}

Refer to Web version on PubMed Central for supplementary material.

\section{ACKNOWLEDGMENT}

Financial support from the MINECO (grant CTQ2015-69136-R (MINECO/FEDER)) and CERCA Program/ Generalitat de Catalunya is gratefully acknowledged. We also thank the MINECO for support through the Severo Ochoa Excellence Accreditation 2014-2018 (SEV-2013-0319). S.C. thanks the MINECO for a Severo Ochoa FPI fellowship (BES-2015-072152). J.M. thanks the National Institutes of Health (R35-GM118133) for support. We are grateful to the ICIQ X-ray diffraction unit for the X-ray single crystal analyses of $\mathbf{4 a}, \mathbf{4 b}$ and $\mathbf{1 0}$. Prof. Ruben Martin (ICIQ) and Dr. Alex J. Nett (University of Michigan) are acknowledged for very useful discussions. We thank Mr. Sergio Fernández (ICIQ) for the assistance on the head-space analysis. 


\section{REFERENCES}

(1). (a)Reppe W; Schlichting O; Klager K; Toepel T Cyclisierende Polymerisation von Acetylen I Über Cyclooctatetraen. Justus Liebig Ann. Chem 1948, 560, 1-92.(b)Wilke G Contributions to Organo-Nickel Chemistry. Angew. Chem. Int. Ed. Engl 1988, 27, 185-206.

(2). (a)Montgomery J Organonickel Chemistry In Organometallics in Synthesis: Fourth Manual; Lipshutz BH, Ed.; Wiley: Hoboken, NJ, 2013; pp 319-428.(b)Tasker SZ; Standley EA; Jamison TF Recent advances in homogeneous nickel catalysis. Nature, 2014, 509, 299-309. [PubMed: 24828188] (c)Standley EA; Tasker SZ; Jensen KL; Jamison TF Nickel Catalysis: Synergy between Method Development and Total Synthesis. Acc. Chem. Res 2015, 48, 1503-1514. [PubMed: 25905431] (d)Thakur A; Louie J Advances in Nickel-Catalyzed Cycloaddition Reactions To Construct Carbocycles and Heterocycles. Acc. Chem. Res 2015, 48, 2354-2365. [PubMed: 26200651] (e)Moslin RM; Miller-Moslin K; Jamison TF Regioselectivity and enantioselectivity in nickel-catalysed reductive coupling reactions of alkynes. Chem. Commun 2007, 4441-4449.

(3). a)Namyslo JC; Kaufmann DE The Application of Cyclobutane Derivatives in Organic Synthesis. Chem. Rev 2003, 103, 1485-1537. [PubMed: 12683789] b)Misale A; Niyomchon S; Maulide N Cyclobutenes: At a Crossroad between Diastereoselective Syntheses of Dienes and Unique Palladium-Catalyzed Asymmetric Allylic Substitutions. Acc. Chem. Res 2016, 49, 2444-2458. [PubMed: 27797480]

(4). (a)Sergeiko A; Poroikov VV; Hanus LO; Dembitsky VM Cyclobutane-containing alkaloids: origin, synthesis, and biological activities. Open Med. Chem. J 2008, 2, 26-37. [PubMed: 19696873] (b)Dembitsky VM Naturally occurring bioactive Cyclobutane-containing (CBC) alkaloids in fungi, fungal endophytes, and plants. Phytomedicine 2014, 21, 1559-1581. [PubMed: 25442265] (c)Chen G; Sasabe H; Igarashi T; Hong Z; Kido J Squaraine dyes for organic photovoltaic cells. J. Mater. Chem. A 2015, 3, 14517-14534.

(5). For examples of nickel-catalyzed activated alkene-alkyne [2+2] cycloaddition reactions, see:Huang D-J; Cheng C-H [2+2] Dimerization of norbornadiene and its derivatives in the presence of nickel complexes and zinc metal. J. Organomet. Chem 1995, 490, C1-C7.Huang D-J; Rayabarapu DK; Li L-P; Sambaiah T; Cheng C-H Nickel-Catalyzed [2+2] Cycloaddition of Alkynes with Activated Cyclic Alkenes: Synthesis and Novel Ring Expansion Studies of Cyclobutene Products. Chem. Eur. J 2000, 6, 3706-3713. [PubMed: 11073240] Saito S; Hirayama K; Kabuto C; Yamamoto Y Nickel(0)-Catalyzed [2+2] Annulation of ElectronDeficient Allenes. Highly Regioselective Synthesis of Cyclobutanes. J. Am. Chem. Soc 2000, 122, 10776-10780.Nishimura A; Ohashi M; Ogoshi S Nickel-Catalyzed Intermolecular [2+2] Cycloaddition of Conjugated Enynes with Alkenes. J. Am. Chem. Soc 2012, 134, 15692-15695. [PubMed: 22966854] Abulimiti A; Nishimura A; Ohashi M; Ogoshi S Nickel-catalyzed [2+2] Cycloaddition Reaction of Bulky Enones with Simple Alkynes. The Effect of Bulkiness of Substituent Attached at $\beta$-Carbon. Chem. Lett 2013, 42, 904-905.Hori H; Arai S; Nishida AA 2Benzothiazolylphenyl Group Accelerates the Intramolecular [2+2] Cycloaddition of Allene Ynes. Asian J. Org. Chem 2014, 3, 41-43.Noucti NN; Alexanian EJ Stereoselective Nickel-Catalyzed [2+2] Cycloadditions of Ene Allenes. Angew. Chem. Int. Ed 2015, 54, 5447-5450.Kumar R; Tamai E; Ohnishi A; Nishimura A; Hoshimoto Y; Ohashi M; Ogoshi S Nickel-Catalyzed Enantioselective Synthesis of Cyclobutenes via [2+2] Cycloaddition of $a, \beta$-Unsaturated Carbonyls with 1,3-Enynes. Synthesis 2016, 48, 2789-2794.Qin H; Chen J; Li K; He Z; Zhou Y; Fan B Nickel Catalyzed Asymmetric [2+2] Cycloaddition Reaction of Hetero Bicyclic Alkenes with Internal Alkynes. Chem. Asian J 2018, DOI: 10.1002/asia.201800492.

(6). For selected examples of [2+2] cycloaddition reactions catalyzed by other metals different than nickel, see:Treutwein J; Hilt G Cobalt-Catalyzed [2+2] Cycloaddition. Angew. Chem. Int. Ed 2008, 47, 6811-6813.López-Carrillo V; Echavarren AM Gold(I)-Catalyzed Intermolecular [2+2] Cycloaddition of Alkynes with Alkenes. J. Am. Chem. Soc 2010, 132, 9292-9294. [PubMed: 20568750] Schotes C; Mezzetti A Enantioselective Ficini Reaction: Ruthenium/PNNP-Catalyzed [2+2] Cycloaddition of Ynamides with Cyclic Enones. Angew. Chem. Int. Ed 2011, 50, 30723074.Nishimura A; Ohashi M; Ogoshi S Nickel-Catalyzed Inter-molecular [2+2] Cycloaddition of Conjugated Enynes with Alkenes. J. Am. Chem. Soc 2012, 134, 15692-15695. [PubMed: 22966854] Nishimura A; Tamai E; Ohashi M; Ogoshi S Synthesis of Cyclobutenes and Allenes 
by Cobalt-Catalyzed Cross-Dimerization of Simple Alkenes with 1,3-Enynes. Chem. Eur. J 2014, 20, 6613-6617. [PubMed: 24782325] de Orbe ME; Echavarren AM Broadening the Scope of the Gold-Catalyzed [2+2] Cycloaddition Reaction: Synthesis of Vinylcyclobutenes and Further Transformations. Eur. J. Org. Chem 2018, 2740-2752.Bai Y-B; Luo Z; Wang Y; Gao J-M; Zhang L Au-Catalyzed Intermolecular [2+2] Cycloadditions between Chloroalkynes and Unactivated Alkenes. J. Am. Chem. Soc, 2018, 140, 5860-5865. [PubMed: 29618202]

(7). For selected examples of Lewis Acid catalyzed [2+2] cycloaddition reactions, see:Snider BB; Rodini DJ; Conn RSE; Sealfon S Lewis acid catalyzed reactions of methyl propiolate with unactivated alkenes. J. Am. Chem. Soc 1979, 101, 5283-5293.Ito H; Hasegawa M; Takenaka Y; Kobayashi T; Iguchi K Enantioselective Total Synthesis of (+)-Tricycloclavulone. J. Am. Chem. Soc 2004, 126, 4520-4521. [PubMed: 15070361] Sweis RF; Schramm MP; Kozmin SA SilverCatalyzed [2 + 2] Cycloadditions of Siloxy Alkynes. J. Am. Chem. Soc 2004, 126, 7442-7443. [PubMed: 15198582] Kang T; Ge S; Lin L; Lu Y; Liu X; Feng X A Chiral $N, N^{\prime}$-Dioxide-Zn II Complex Catalyzes the Enantioselective [2+2] Cycloaddition of Alkynones with Cyclic Enol Silyl Ethers. Angew. Chem. Int. Ed 2016, 55, 5541-5544.Shen L; Zhao K; Doitomi K; Ganguly R; Li Y-X; Shen Z-L; Hirao H; Loh T-P Lewis Acid-Catalyzed Selective [2+2]-Cycloaddition and Dearomatizing Cascade Reaction of Aryl Alkynes with Acrylates. J. Am. Chem. Soc 2017, 139, 13570-13578. [PubMed: 28880536]

(8). Liu Y; Liu M; Song Z Highly Regio- and Stereoselective Synthesis of Tetrasubstituted Cyclobutenes via Cyclodimerization of Alkynes Mediated by Zirconium. J. Am. Chem. Soc 2005, 127, 3662-3663. [PubMed: 15771477]

(9). For examples using primary $\beta$-aminophosphine ligands, see:Abdur-Rashid K; Guo R; Lough AJ; Morris RH; Song D Synthesis of Ruthenium Hydride Complexes Containing beta Aminophosphine Ligands Derived from Amino Acids and their use in the $\mathrm{H}_{2}$-Hydrogenation of Ketones and Imines. Adv. Synth. Catal 2005, 347, 571-579.Guo M; Jian F; He R The air-stable and highly efficient P,N-chelated palladium(II) complexes as catalysts for the Suzuki crosscoupling reaction at room temperature Tetrahedron Lett. 2006, 45, 2033-2036.John JM; Bergens SH A Highly Active Catalyst for the Hydrogenation of Amides to Alcohols and Amines. Angew. Chem. Int. Ed 2011, 50, 10377-10380.Higuchi T; Tagawa R; Iimuro A; Akiyama S; Nagae H; Mashima K Tunable Ligand Effects on Ruthenium Catalyst Activity for Selectively Preparing Imines or Amides by Dehydrogenative Coupling Reactions of Alcohols and Amines. Chem. Eur. J 2017, 23, 12795-12804. [PubMed: 28557018] Van Putten R; Uslamin EA; Garbe M; Liu C; Gonzalez-de-Castro A; Lutz M; Junge K; Hensen EJM; Beller M; Lefort L; Pidko EA NonPincer-Type Manganese Complexes as Efficient Catalysts for the Hydrogenation of Esters. Angew. Chem. Int. Ed 2017, 56, 7531-7534.For a review on the use of tertiary $\beta$ aminophosphine ligands, see:Li W; Zhang J Recent developments in the synthesis and utilization of chiral $\beta$-aminophosphine derivatives as catalysts or ligands. Chem. Soc. Rev 2016, 45, 16571677. [PubMed: 26776280]

(10). See Supporting Information for more details.

(11). Functional groups such as nitrile, aldehyde, amide, ester, ketone, bromide, phenol, alcohols, pyridine, alkenes and amine were tolerated, while imidazole shut down the desired reaction. See Supporting Information for more details.Collins KD; Glorius F A robustness screen for the rapid assessment of chemical reactions. Nat. Chem 2013, 5, 597-601. [PubMed: 23787750]

Richardson J; Ruble JC; Love EA; Berritt S A Method for Identifying and Developing Functional Group Tolerant Catalytic Reactions: Application to the Buchwald-Hartwig Amination. J. Org. Chem 2017, 82, 3741-3750. [PubMed: 28245358]

(12). This migration observed gives support to the cationic species proposed to be generated at $\beta$ position of the silyl group (species V on Scheme 5). For selected examples of silyl group migrations to $\beta$-cationic positions, see:Groaning MD; Brengel GP; Meyers A I.

Allyldimethyltritylsilane. Synthesis of Cyclopentanols, Oxetanes, and Tetrahydrofurans by Reaction with Electron Deficient Olefins. J. Org. Chem 1998, 63, 5517-5522.Knölker H-J; Baum E; Graf R; Jones PG; Spieb O An Unprecedented Domino Double Allylsilane [3+2] Cycloaddition/Wagner-Meerwein Rearrangement/Friedel-Crafts Alkylation/Elimination Reaction Sequence Leading to a Novel Pentacyclic Ring System. Angew. Chem. Int. Ed 1999, 38, 2583 2585.Ball-Jones NR; Badillo JJ; Tran NT; Franz AK Catalytic Enantioselective Carboannulation with Allylsilanes. Angew. Chem. Int. Ed 2014, 53, 9462-9465. 
(13). a)Oblinger E; Montgomery J A New Stereoselective Method for the Preparation of Allylic Alcohols. J. Am. Chem. Soc 1997, 119, 9065-9066.b)Montgomery J Nickel Catalyzed Reductive Cyclizations and Couplings. Angew. Chem. Int. Ed 2004, 43, 3890-3908.c)Malik HA; Sormunen GJ; Montgomery J A General Strategy for Regiocontrol in Nickel-Catalyzed Reductive Couplings of Aldehydes and Alkynes. J. Am. Chem. Soc 2010, 132, 6304-6305. [PubMed: 20394367] d)Todd DP; Thompson BB; Nett AJ; Montgomery J Deoxygenative C-C BondForming Processes via a Net Four-Electron Reductive Coupling. J. Am. Chem. Soc 2015, 137, 12788-12791. [PubMed: 26436636] e)Wang H; Lu G; Sormunen GJ; Malik HA; Liu P; Montgomery J NHC Ligands Tailored for Simultaneous Regio- and Enantiocontrol in NickelCatalyzed Reductive Couplings. J. Am. Chem. Soc 2017, 139, 9317-9324. [PubMed: 28621131] f)Nett AJ; Cañellas S; Higuchi Y; Robo MT; Kochkodan JM; Haynes MT II; Kampf JW; Montgomery J Stable, Well-Defined Nickel(0) Catalysts for Catalytic C-C and C-N Bond Formation. ACS Catal. 2018, 8, 6606-6611. [PubMed: 30079273]

(14). Igarashi T; Haito A; Chatani N; Tobisu M Nickel-Catalyzed Reductive Cleavage of CarbonOxygen Bonds in Anisole Derivatives Using Diisopropylaminoborane. ACS Catal. 2018, 8, 7475-7483.

(15). The major diastereomer is a trans-cyclobutene. However, attempts to obtain crystals of $2 \mathrm{~s}$, or derivatives thereof, suitable for X-ray crystal analysis have been unsuccessful.

(16). Reichard HA; McLaughlin M; Chen MZ; Micalizio GC Regioselective Reductive CrossCoupling Reactions of Unsymmetrical Alkynes. Eur. J. Org. Chem 2010, 391-409.

(17). The hypothetical trans-1,2,3,4-tetraphenylcyclobutene is known to undergo rapid ring-opening to afford the corresponding cis, cis-1,2,3,4-tetraphenyl-1,3-butadiene 4a. See:Freedman HH; Doorakian GA; Sandel VR The Valence Isomerization of 1,2,3,4-Tetraphenylcyclobutene and Its Anion. J. Am. Chem. Soc 1965, 87, 3019-3020.Lee PS; Sakai S; Hörstermann P; Roth WR; Kallel EA; Houk KN Altering the Allowed/Forbidden Gap in Cyclobutene Electrocyclic Reactions: Experimental and Theoretical Evaluations of the Effect of Planarity Constraints. J. Am. Chem. Soc 2003, 125, 5839-5848. [PubMed: 12733925]

(18). The diene structures of $4 \mathrm{a}$ and $4 \mathrm{~b}$ were unambiguously confirmed by single X-ray crystal analyses. See the Supporting Information file.

(19). For a selected example, see:Arnó M; Betancur-Galvis L; González MA; Sierra J; Zaragozá RJ Synthesis and cytotoxic activity of novel C7-Functionalized spongiane diterpenes. Bioorganic Med. Chem 2003, 11, 3171-3177.

(20). For a selected example, see:Paquette LA; Wang T-Z; Cottrell CE Flattening of the cyclooctatetraene ring by annulation. J. Am. Chem. Soc 1987, 109, 3730-3734.

(21). Baumann AN; Schüppel F; Eisold M; Kreppel A; de Vivie-Riedle R; Didier D Oxidative Ring Contraction of Cyclobutenes: General Approach to Cyclopropylketones including Mechanistic Insights. J. Org. Chem 2018, 83, 4905-4921. [PubMed: 29641195]

(22). a)Liebermann C Ueber Cinnamylcocaïn. Ber. Dtsch. Chem. Ges 1888, 21, 3372-3376.b)Pictet A in The Vegetable Alkaloids, With Particular Reference to Their Chemical Constitution, Wiley, New York, 1913, p. 236.

(23). Antinociceptive activity:Chi Y-M; Nakamura M; Zhao X-Y; Yoshizawa T; Yan W-M; Hashimoto F; Kinjo J; Nohara T; Sakurada S Antinociceptive Activities of a-Truxillic Acid and $\beta$-Truxinic Acid Derivatives. Biol. Pharm. Bull 2006, 29, 580-584. [PubMed: 16508173] Kaczocha M; Glaser ST; Deutsch DG Identification of intracellular carriers for the endocannabinoid anandamide. Proc. Natl. Acad. Sci. USA 2009, 106, 6375. [PubMed: 19307565] Liu SX; Jin HZ; Shan L; Zeng HW; Chen BY; Sun QY; Zhang WD Inhibitory effect of 4,4'-dihydroxy-a-truxillic acid derivatives on NO production in lipopolysaccharide-induced RAW 264.7 macrophages and exploration of structure-activity relationships. Bioorg. Med. Chem. Lett 2013, 23, 2207-2211. [PubMed: 23454014] Antimuscarinic activity:Lysíková M; Fuksová K; Elbert T; Jakubík J; Tuĉek S Subtype-selective inhibition of [methyl-3H]-N-methylscopolamine binding to muscarinic receptors by a-truxillic acid esters. Br. J. Pharmacol 1999, 127, 1240-1246. [PubMed: 10455271]

(24). Please note that products 8 and 9 are meso compounds, so they lack chirality. 
(25). This isomeric form possessing a characteristic S1 axis is easily distinguished by NMR from the other isomers of truxillic acid, 20 and the structure of 9 was unambiguously assigned by single $\mathrm{X}$-ray crystal of its methyl ester 10. See the Supporting Information file.

(26). For a selected examples of Jones oxidation reactions, see:Bowden K; Heilbron IM; Jones ERH; Weedon BCL 13. Researches on acetylenic compounds. Part I. The preparation of acetylenic ketones by oxidation of acetylenic carbinols and glycols. J. Chem. Soc 1946, 0, 39-45.Heller L; Schwarz S; Perl V; Köwitsch A; Siewert B; Csuk R Incorporation of a Michael acceptor enhances the antitumor activity of triterpenoic acids. Eur. J. Med. Chem 2015, 101, 391-399. [PubMed: 26177446]

(27). Gómez-Gallego M; Sierra MA Kinetic Isotope Effects in the Study of Organometallic Reaction Mechanisms. Chem. Rev 2011, 111, 4857-4963. [PubMed: 21545118]

(28). At present, we cannot rule out other mechanistic interpretation of these results. For further insight on linear free energy relationships, see:Wells PR Linear Free Energy Relationships. Chem. Rev 1963, 63, 171-219.

(29). Kinetic analyses of the model reaction with different L1:Ni ratios (1:1, 2:1 and 4:1) suggest that the active species consist of equimolar quantities of ligand and nickel. However, the use of an excess of ligand prevents the generation of other byproducts, achieving higher yield of the desired cyclobutene. See Supporting Information file for more details.

(30). a)Ogoshi S; Oka M, Kurosawa H Direct Observation of Oxidative Cyclization of $\eta 2$-Alkene and १2-Aldehyde on $\mathrm{Ni}(0)$ Center. Significant Acceleration by Addition of Me3SiOTf. J. Am. Chem. Soc 2004, 126, 11802-11803. [PubMed: 15382909] b)Hong X; Holte D; Götz DCG; Baran PS; Houk KN Mechanism, Reactivity, and Selectivity of Nickel-Catalyzed [4+4+2] Cycloadditions of Dienes and Alkynes. J. Org. Chem 2014, 79, 12177-12184. [PubMed: 25325891] c)Ma W; Yu C; Chen T; Xu L; Zhang W-X; Xi Z Metallacyclopentadienes: synthesis, structure and reactivity. Chem. Soc. Rev 2017, 46, 1160-1192. [PubMed: 28119972]

(31). (a)Takahashi G; Shirakawa E; Tsuchimoto T; Kawakami Y Nickel-Catalyzed Addition of Organoboronates to 1,2-Dienes and the Corresponding Three-Component Reaction with an Alkyne. Adv. Synth. Catal 2006, 348, 837-840.(b)Xiao L-J; Cheng L; Feng W-M; Li M-L; Xie JH; Zhou Q-L Nickel(0)-Catalyzed Hydroarylation of Styrenes and 1,3-Dienes with Organoboron Compounds. Angew. Chem. Int. Ed 2018, 57, 461-464.(c)Han X-W; Zhang T; Zheng Y-L; Yao W-W; Li J-F; Pu Y-G; Ye M; Zhou Q-L Brønsted Acid Enabled Nickel-Catalyzed Hydroalkenylation of Aldehydes with Styrene and its Derivatives. Angew. Chem. Int. Ed 2018, 57, 5068-5071.

(32). This transformation is possibly the rate-determining step, as suggested by the mechanistic experiments, since it involves both the formation of a cation and a proton transfer of the former methanol proton.

(33). For examples of nickel carbene intermediates, see:Barluenga J; Barrio P; López LA; Tomás M; García-Granda S; Alvarez-Rúa C Nickel(0)-Mediated [3+2+2] and [2+2+2+1] Cyclization Reactions of Chromium Fischer Carbene Complexes and Alkynes. Angew. Chem. Int. Ed 2003, 42, 3008-3011.Ni Y; Montgomery, J. Synthetic Studies and Mechanistic Insight in NickelCatalyzed [4+2+1] Cycloadditions. J. Am. Chem. Soc 2006, 128, 2609-2614. [PubMed: 16492045]

(34). a)Kocieński P; Barber C Synthetic applications of metallate rearrangements. Pure \& Appl. Chem 1990, 62, 1933-1940.b)Clement ND; Cavell KJ Transition-Metal-Catalyzed Reactions Involving Imidazolium Salt/N Heterocyclic Carbene Couples as Substrates. Angew. Chem. Int. Ed 2004, 43, 3845-3847.c)Steinke T; Shaw BK; Jong H; Patrick BO; Fryzuk MD; Green JC Noninnocent Behavior of Ancillary Ligands: Apparent Trans Coupling of a Saturated N-Heterocyclic Carbene Unit with an Ethyl Ligand Mediated by Nickel. J. Am. Chem. Soc 2009, 131, 10461-10466. [PubMed: 19585991]

(35). Head-space analysis reveals the generation of ethylene in the reaction. See Supporting Information file for more details.

(36). a)Patel SJ; Jamison TF Catalytic Three-Component Coupling of Alkynes, Imines, and Organoboron Reagents. Angew. Chem. Int. Ed 2003, 42, 1364-1367.b)Molinaro C; Jamison TF Nickel-Catalyzed Reductive Coupling of Alkynes and Epoxides. J. Am. Chem. Soc 2003, 125, 8076-8077. [PubMed: 12837057] (c)McCarren PR; Liu P; Cheong PH-Y; Jamison TF; Houk KN 
Mechanism and Transition-State Structures for Nickel-Catalyzed Reductive Alkyne-Aldehyde Coupling Reactions. J. Am. Chem. Soc 2009, 131, 6654-6655. [PubMed: 19397371]

(37). (a)Herath A; Montgomery J Catalytic Intermolecular Enal-Alkyne [3+2] Reductive Cycloadditions. J. Am. Chem. Soc 2006, 128, 14030-14031. [PubMed: 17061877] (b)Jenkins AD; Herath A; Song M; Montgomery J Synthesis of Cyclopentenols and Cyclopentenones via Nickel-Catalyzed Reductive Cycloaddition. J. Am. Chem. Soc 2011, 133, 14460-14466. [PubMed: 21819132] c)Ohashi M; Taniguchi T; Ogoshi S Nickel-Catalyzed Formation of Cyclopentenone Derivatives via the Unique Cycloaddition of a, $\beta$-Unsaturated Phenyl Esters with Alkynes. J. Am. Chem. Soc 2011, 133, 14900-14903. [PubMed: 21877707]

(38). For other examples of reductive cycloaddition:Enholm EJ; Kinter KS Free radical cyclizations promoted by allylic O-stannyl ketyls: the intramolecular coupling of the beta-carbons of activated alkenes. J. Am. Chem. Soc 1991, 113, 7784-7785.Hays DS; Fu GC Organotin Hydride Catalyzed Carbon-Carbon Bond Formation: Radical-Mediated Reductive Cyclization of Enals and Enones. J. Org. Chem 1996, 61, 4-5.Savchenko AV; Montgomery J Organozinc/Nickel(0)Promoted Cyclizations of Bis-Enones. J. Org. Chem 1996, 61, 1562-1563. [PubMed: 11667020] Lee J; Kim H; Cha JK A New Variant of the Kulinkovich Hydroxycyclopropanation. Reductive Coupling of Carboxylic Esters with Terminal Olefins J. Am. Chem. Soc 1996, 118, 41984199.Kulinkovich OG The Chemistry of Cyclopropanols. Chem. Rev 2003, 103, 2597-2632. [PubMed: 12848581] Zhou YY; Uyeda C Reductive Cyclopropanations Catalyzed by Dinuclear Nickel Complexes. Angew. Chem. Int. Ed 2016, 55, 3171-3175.

(39). Kinetic profile of the reaction for the formation of $2 \mathrm{c}$ in the presence of 1 equivalent of $\mathrm{E}$ - and Z$\beta$-methylstyrene overlap with the one where no additive is added. See kinetic analyses in the Supporting Information file. 
a) Alkene-alkyne [2+2]-cycloaddition

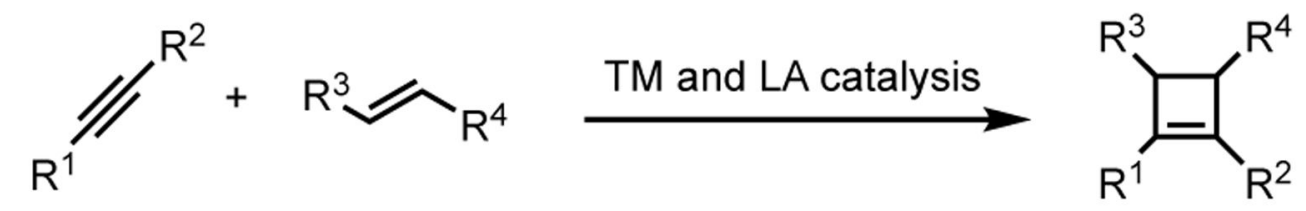

b) Zirconium-mediated reductive cyclodimerization of ortho-alkynylpyridines<smiles>[R]C#Cc1[X]cccn1</smiles><smiles>CC/C=C(\CC)CCCCC(=O)O[N+](=O)[O-]</smiles><smiles>[R]C1=C(c2ncccn2)C([R])[C@H]1c1[X]cccn1</smiles>

c) This work

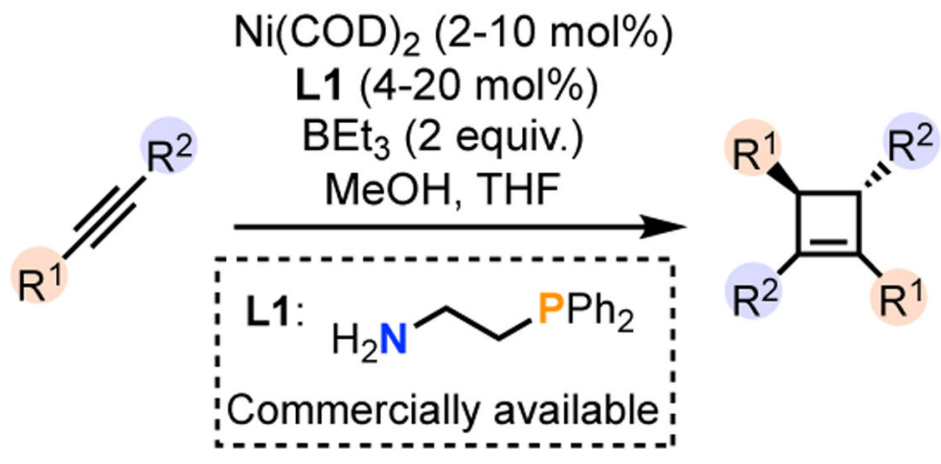

- Excellent regio- and stereoselectivity

Figure 1.

Approaches towards the synthesis of cyclobutenes 


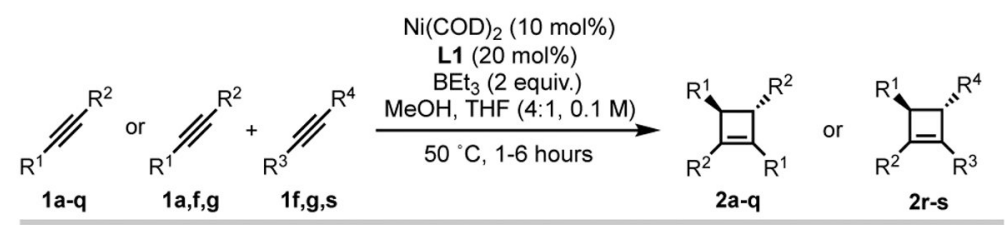

Homocycloaddition products
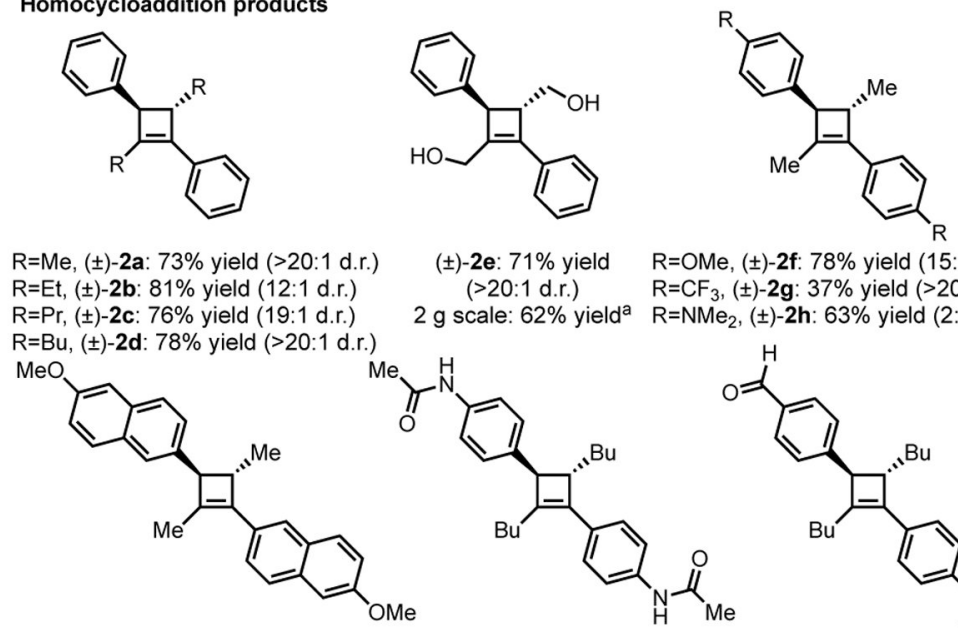

( \pm -2i: $69 \%$ yield (>20:1 d.r.)

( \pm )-2j: $51 \%$ yield (16:1 d.r.)

(土)-2k: $32 \%$ yield $\left(16:{ }_{1}^{\mathrm{H}}\right.$ d.r. $)$

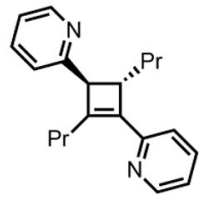

( \pm )-2l: $71 \%$ yield (>20:1 d.r.)

TMS-migrated products

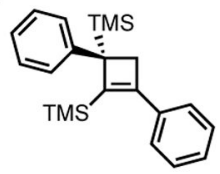

( \pm -2p: $37 \%$ yield $(10: 1$ r.r.) Heterocycloaddition products $\mathrm{F}_{3} \mathrm{C}$

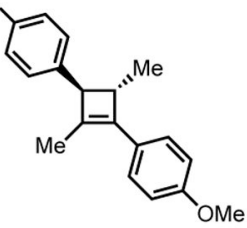

(士)-2r: $62 \%$ yield $(1: 1 \mathrm{r} . \mathrm{r}$.

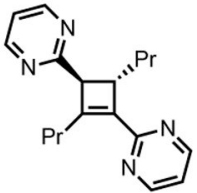

(士)-2n: $60 \%$ yield (>20:1 d.r.)

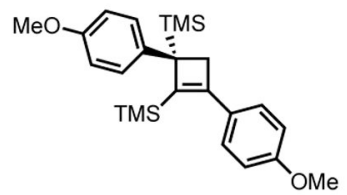

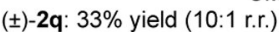

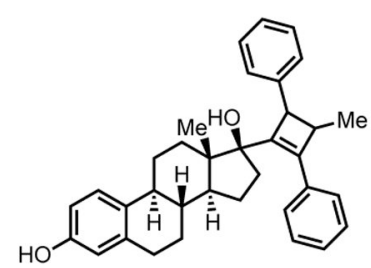

2s: $59 \%$ yield $(10: 1 \text { d.r., } 40 \% \text { rsm })^{\text {b }}$

Scheme 1.

Substrate scope. Isomeric ratios (d.r. and r.r.) calculated by GC-FID. ${ }^{\mathrm{a}} \mathrm{Ni}(\mathrm{COD})_{2}(2 \mathrm{~mol} \%)$ and L1 (4 mol \%) were used. ${ }^{b}$ See reference 15. 
a)

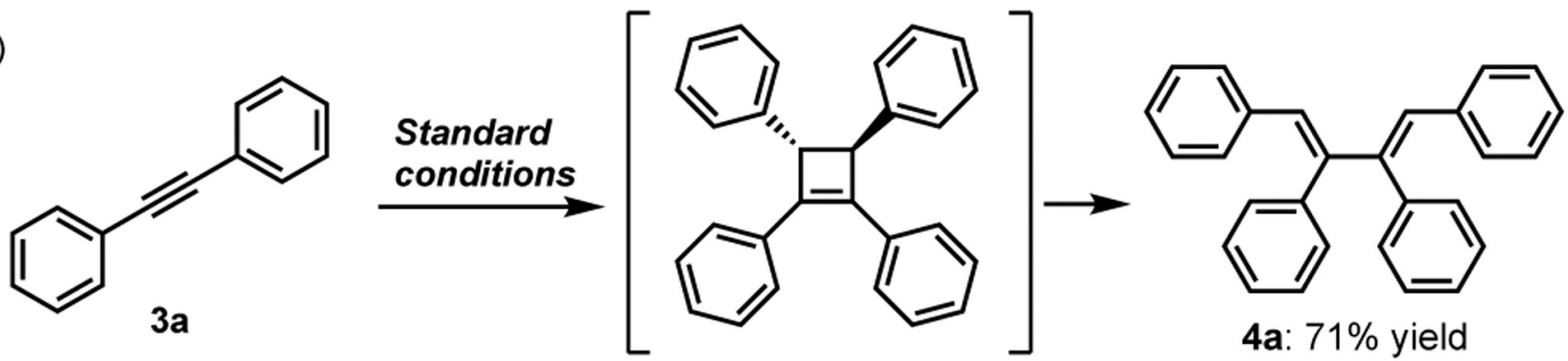

b)<smiles>CN1C(=O)C(CC#Cc2ccccc2)(CC#Cc2ccccc2)c2ccccc21</smiles>

$3 b$

3c

Scheme 2. towards dienes.

\section{Standard} conditions

\section{Standard} conditions
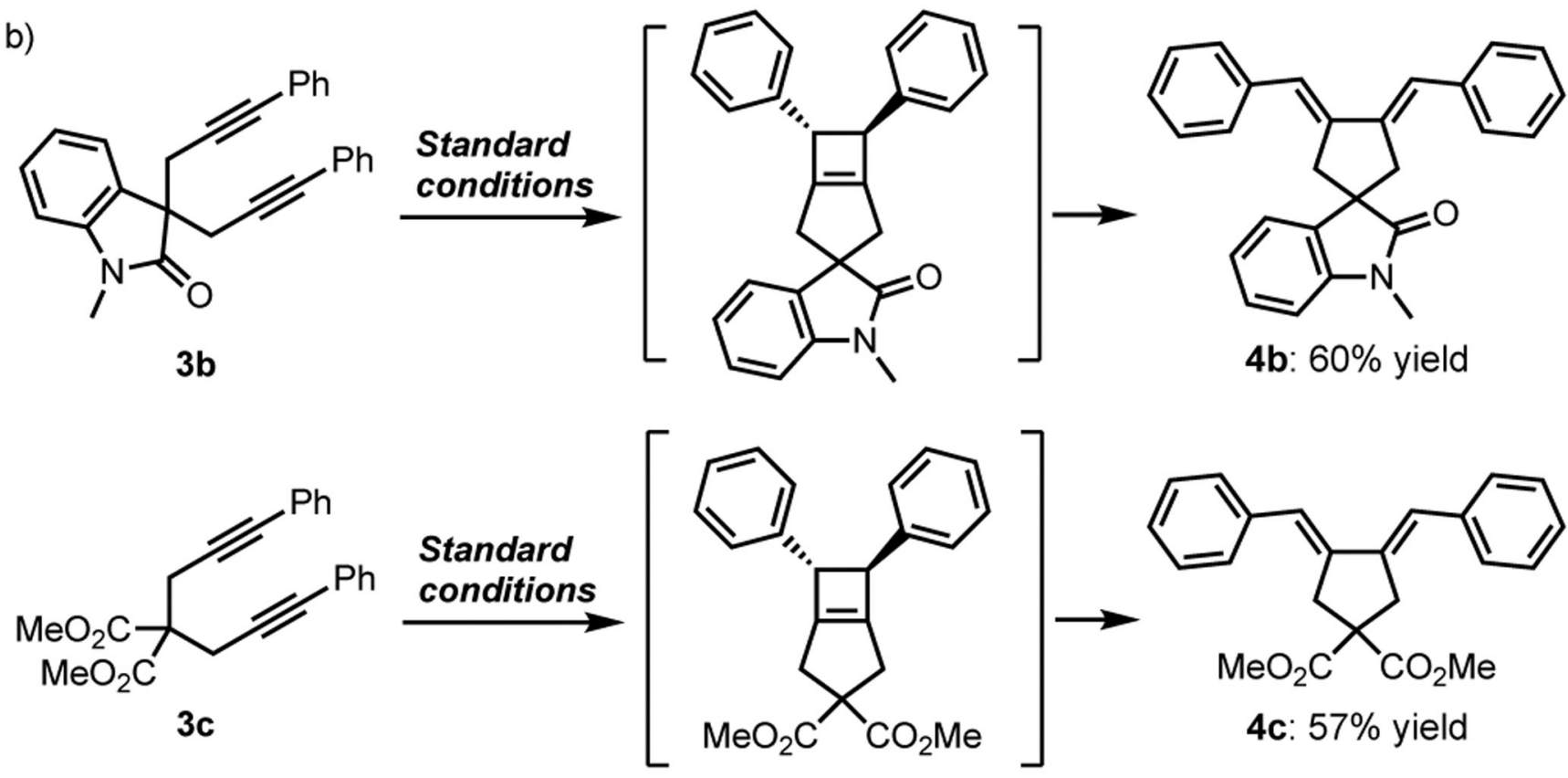

4b: $60 \%$ yield<smiles>COCC1(C(=O)OC)CC2=C(C1)[C@H](c1ccccc1)[C@H]2c1ccccc1</smiles>
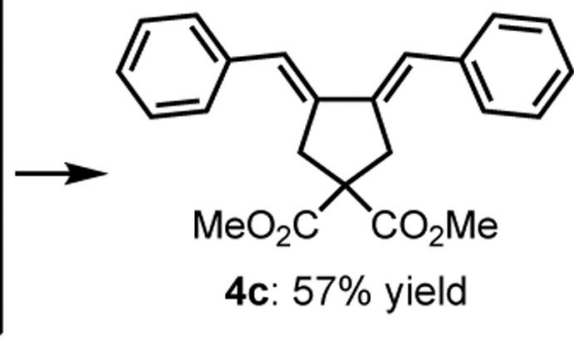

4c: $57 \%$ yield

a) Reductive homocoupling of diphenylacetylene. b) Reductive cyclization of diynes 


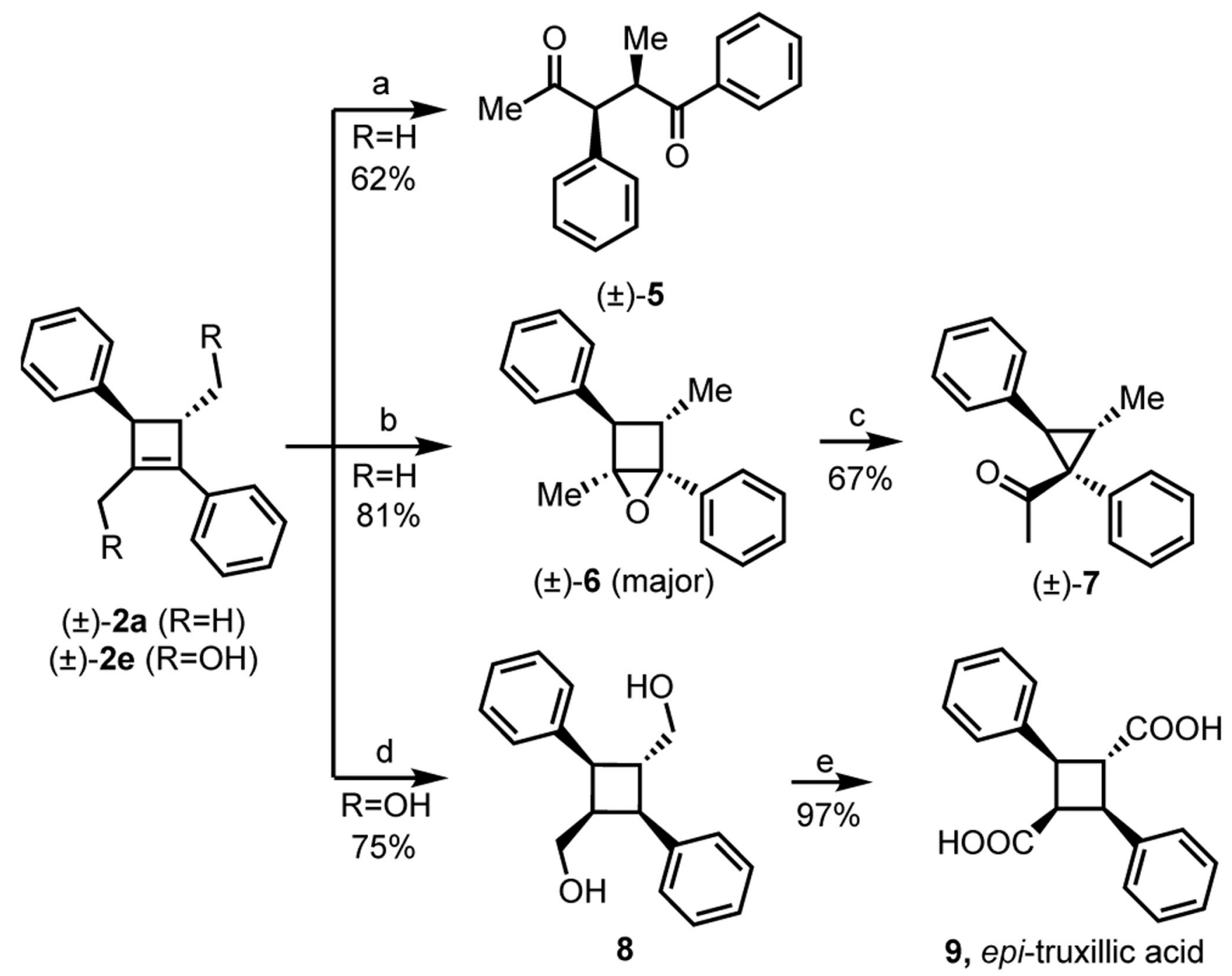

Scheme 3.

Synthetic diversification of cyclobutene $2 \mathbf{a}$ and $2 \mathbf{f}$. a) $\mathrm{O}_{3}, \mathrm{CHCl}_{3},-78{ }^{\circ} \mathrm{C}$. b) $\mathrm{m}$-CPBA, $\mathrm{NaHCO}_{3}, \mathrm{CHCl}_{3}, \mathrm{O}^{\circ} \mathrm{C}$. c) aq $\mathrm{HCl}(0.1 \mathrm{M})$, rt. d) $\mathrm{H}-\mathrm{Cube}, 1 \mathrm{~mL} / \mathrm{min}, \mathrm{H}_{2}$ (60 bar), $\mathrm{Pd} / \mathrm{C}$ (10\%), $60{ }^{\circ} \mathrm{C}, \mathrm{MeOH}(0.25 \mathrm{M})$. e) $\mathrm{CrO}_{3}, \mathrm{H}_{2} \mathrm{SO}_{4}, \mathrm{H}_{2} \mathrm{O}$, acetone. 
a)

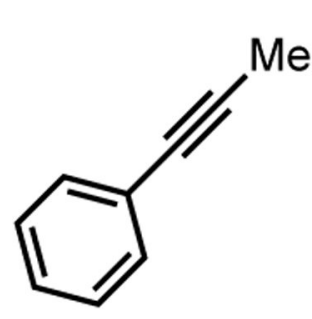

$1 a$

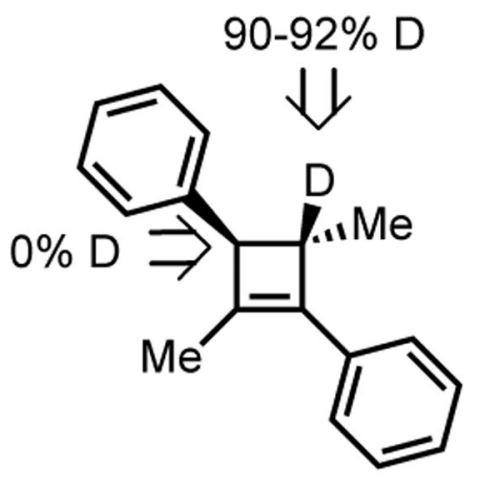

with $\mathrm{CD}_{3} \mathrm{OD}$

b)
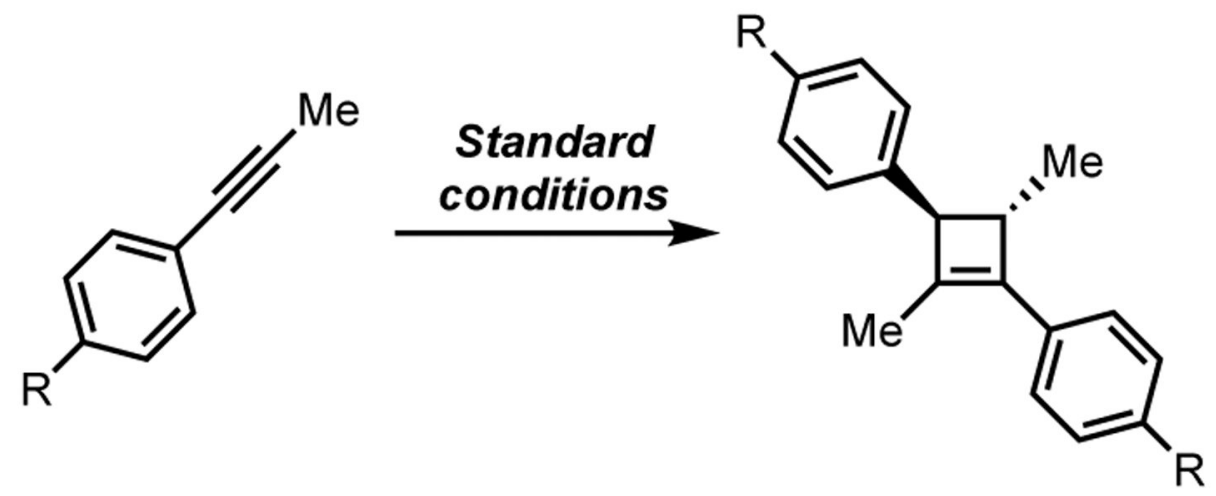

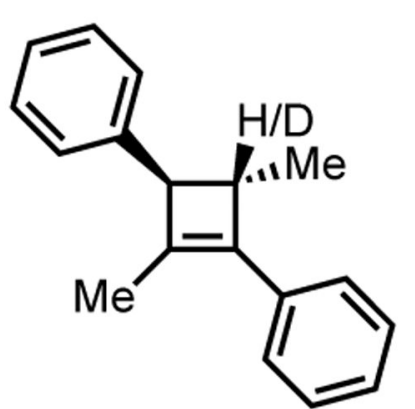

$\mathbf{2} \mathbf{a}$ or $\mathbf{2} \mathbf{a}-d$

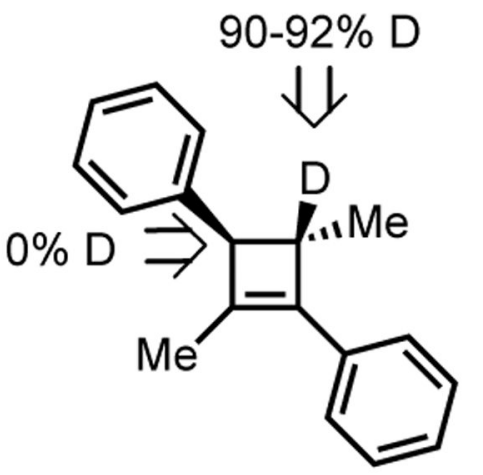

with $\mathrm{CH}_{3} \mathrm{OD}$

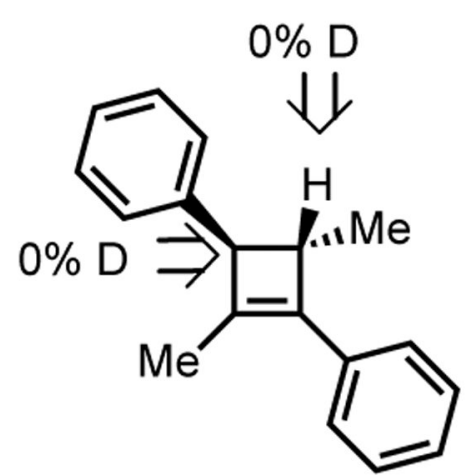

with $\mathrm{CD}_{3} \mathrm{OH}$

$$
\begin{aligned}
& \mathrm{R}=\mathrm{NMe}_{2}(\mathbf{2 h}) \\
& \mathrm{R}=\mathrm{OMe}(\mathbf{2 f}) \\
& \mathrm{R}=\mathrm{H}(\mathbf{2 a}) \\
& \mathrm{R}=\mathrm{CF}_{3}(\mathbf{2 g}) \\
& \rho=-\mathbf{0 . 5 8}
\end{aligned}
$$

Scheme 4.

Mechanistic experiments. 


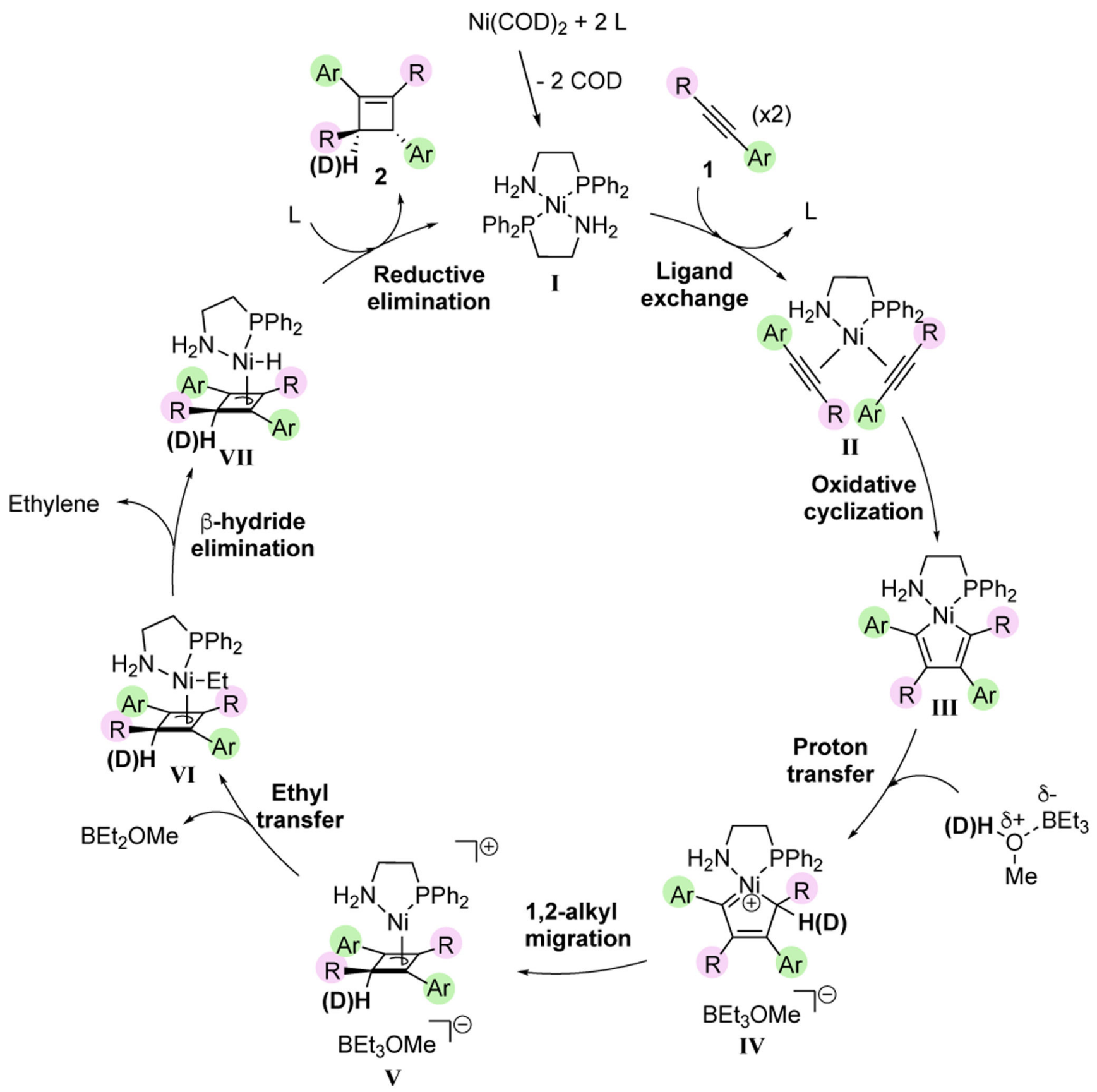

Scheme 5.

Proposed catalytic cycle. 
Table 1.

Screening and optimization of the reaction conditions. ${ }^{a}$

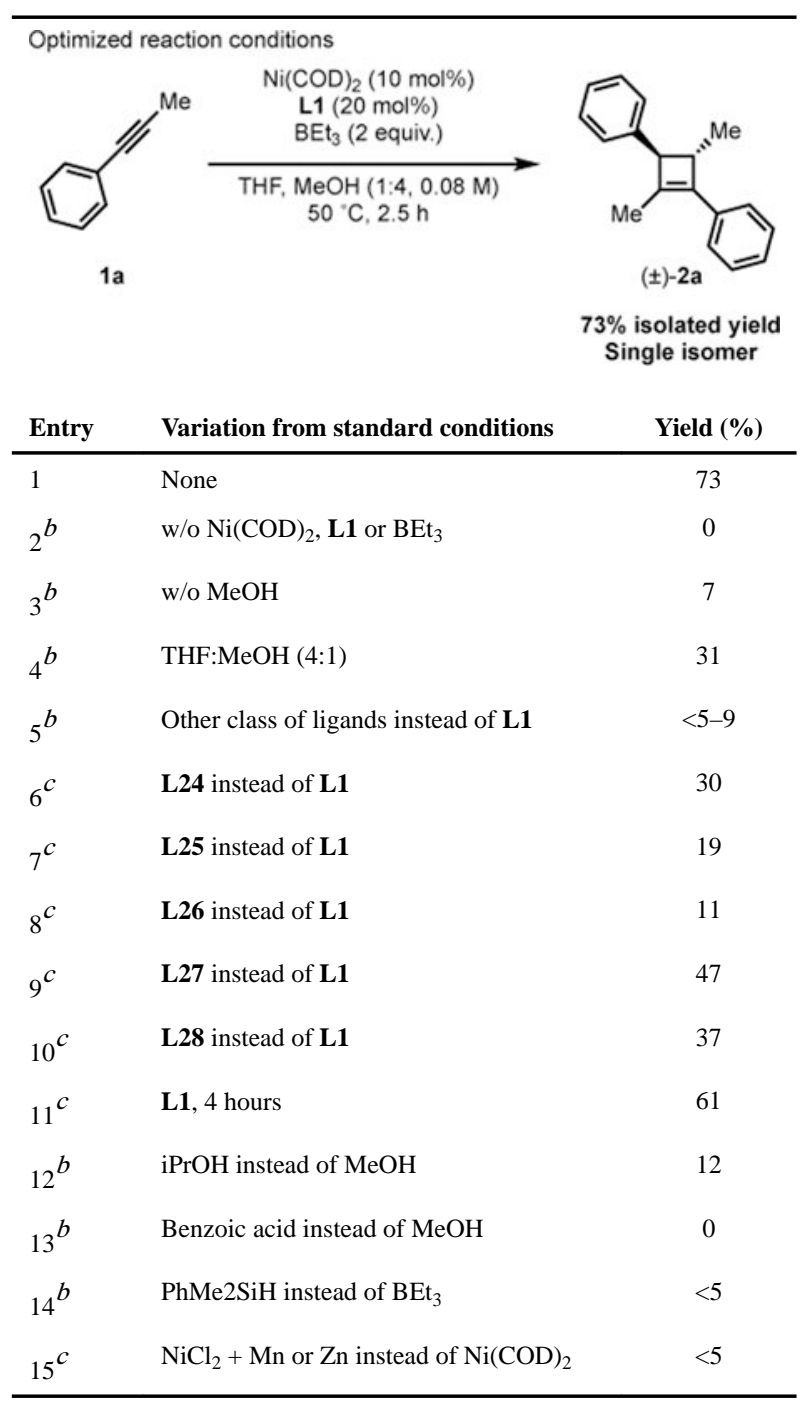

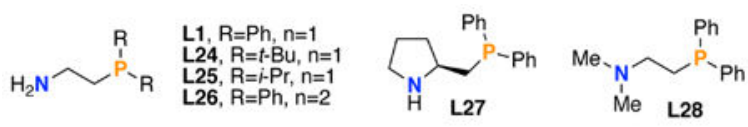

${ }^{a}$ Optimized reaction conditions: 1a $(0.45 \mathrm{mmol}), \mathrm{Ni}(\mathrm{COD}) 2(0.045 \mathrm{mmol}), \mathbf{L 1}(0.09 \mathrm{mmol}), \mathrm{BEt} 3(0.9 \mathrm{mmol}), \mathrm{THF}: \mathrm{MeOH}(1: 4 \mathrm{ratio}, 0.08 \mathrm{M})$, $50^{\circ} \mathrm{C}, 2.5 \mathrm{~h}$.

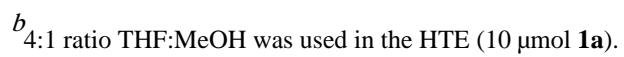

$c_{4 \text { hours. }}$ 